\title{
DOMESTIC VIOLENCE: PUBLIC REACTIONS AND STRATEGIC INTERVENTIONS
}

\author{
Syazliana Astrah Mohd Idris ${ }^{*}$, Nor Fadilah Mohamed Nizar ${ }^{1}$, Khalilah A. Rasip ${ }^{1}$, \\ Nurul Nadia Abd Aziz², Raja Kamariah Raja and Mohd Khalid ${ }^{3}$ \\ ${ }^{1}$ Johor Empowerment of Intellectual Women Association, Ministry of Women, Family and Society Development, \\ Malaysia \\ ${ }^{2}$ Faculty of Business Management, University Technology of MARA, Pahang, Malaysia \\ ${ }^{3}$ Department of Women's Development, Ministry of Women, Family and Society Development, Malaysia
}

\begin{abstract}
This paper was prepared as part of the Domestic Violence against Women Research Project conducted by JEIWA's Research and Innovation (R\&I) with the support of Department of Women's Development, Malaysia. The paper seeks to explore the factors that contribute to the public reactions to domestic violence against woman and strategic interventions in increasing public awareness. Violence against women deprives women of their right to fully take part in social and economic life. It causes a myriad of physical and mental health issues. An extensive investigation of related literature and in-depth interview with domestic violence witnesses are employed for this purpose. The key findings of this study found that the culture and tradition, social stigma and lack of knowledge of public's right have been identified as the factors that hinder the community to response to domestic violence perpetration. The findings from this research could help policy makers, authorized agencies and non-governmental organizational leaders to strategize and adequately craft a suitable and high impact program that suits the target groups' needs and lifestyle.
\end{abstract}

Keywords: culture and tradition; strategic interventions; lack of knowledge; reactions; social stigma

\section{Introduction}

Domestic violence is a global problem that crosses cultural, geographic, religious, social and economic boundaries and is a violation of human rights. Domestic violence deprives women of their right to fully take part in social and economic life which has serious impacts on women's health and well-being (Idris et al., 2018). Moreover, Domestic violence is a complicated and difficult issue to study and the research findings are inconsistent (Khan, 2015; Shuib et al., 2013).

Domestic violence is often described as a family-centred problem and generally understood as patterns of abusive and coercive behaviour, which may cause physical injuries, psychological and emotional disturbances, sexual intimidation as well as financial oppression of the victim (Ghani, 2014). There are many definitions of domestic violence, according to the World Health Organisation (WHO, 2013), domestic violence can be defined as the intentional use of physical force or power, threatened or actual, against women, which either results in or has a high likelihood of resulting in injury, death, psychological harm, maldevelopment or deprivation.

Meanwhile, the Department of Public Health and Innovation, England, identifies domestic violence as any incident or pattern of incidents of controlling, coercive or threatening behaviour, violence or abuse between those aged 16 or over who are or have been, intimate partners or family members regardless of gender or sexuality. However, this study focuses on domestic violence against women that have been abused by husband or intimate partner. The abuse can encompass, but is not limited to psychological, physical, sexual, financial, and emotional that disproportionately impact on women, is a violation of women's fundamental rights with respect to dignity, equality and access to justice. 


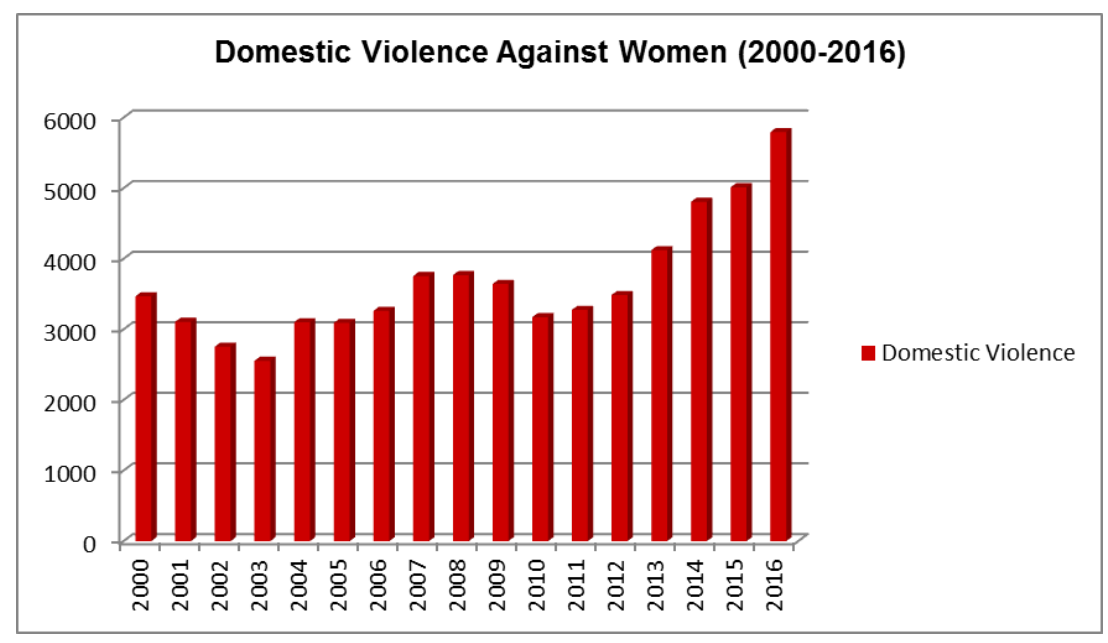

Figure 1 Total Domestic Violence Cases against Women from 2000 to 2016 in Malaysia (Source: Extracted from Ministry of Women, Family and Society Development, Royal Malaysian Police and Parliament of Malaysia).

According to statistics released by the Malaysian Royal Police in Parliament last session, 62,670 domestic violence cases were reported from 2000 to January 2017 with an estimated3,800 cases per year equivalent to 323 cases per month (Parliament of Malaysia, 2017), (refer figure 1). Furthermore, domestic violence cases have recorded a sharp increase of 66\% between 2012 (3,488 cases) and 2016 (5,796 cases). Based on the latest statistics in 2016 that are sourced from the Royal Malaysia Police and Ministry of Women, Family and Community Development, urgent attention is needed to study this matter because the data showed that cases of domestic violence are increasing every year, and has been recorded as the highest form of violence against women in Malaysia for more than a decade (Idris et al., 2018). Despite various steps have been taken by governmental and enforcement agencies as well as non-governmental organisations (NGOs), the problem of domestic violence is still at its most serious level.

Hence, what causes domestic violence? Why the percentages of domestic violence rising despite the various campaigns, awareness programs and enforcement of the act have been carried out? What society should (and should not) do when it occurs? There are many more questions that cannot be answered and resolved even though the issue of violence against women has long been widespread (García-moreno, Claudia; Jansen, Henrica; Ellsberg, Mary; Heise, Lori; and Watts, 2005; Uzun \& Uzunboylu, 2015). There are many studies and many interventions regarding domestic violence have been conducted but the problem continues to rise in today's society. Very little has been known about the prevalence of domestic violence in Malaysia and there has been a real need for evidence to learn more about the prevalence, causes and consequences of domestic violence (Aziz, Idris, Ishak, Wahid, \& Yazid, 2018a; Idris et al., 2018). It is believed that the outputs from empirical research are the key elements in proposing any possible solutions to overcome this problem.

In view of this, there is a need to explore on the nature and extent of public reactions or response to domestic violence. More aggressive enforcement and strategic interventions for victim's protection and support system, especially in combating domestic violence are closely related to assumptions about what the public knows and believes about domestic violence and what they should do when it happens in public area. Furthermore, the effectiveness of these strategies may be influenced by contextual factors such as community perception that support or oppose public responsibility. Understanding public attitudes and the extent of public knowledge about domestic violence is crucial because community perceptions about this complex social problem form the context in which public policy is formulated and criminal justice agencies respond. People may not report victimization because they expect an unhelpful response and have lack of knowledge about their rights, they may fear or they simply believe that despite good intentions, the law cannot protect victims. For the same reasons, friends or relatives may ignore victims and discourage her from reporting violent incidents. Hence, the purpose of this research is to learn more about the nature of public responsiveness toward domestic 
violence against women by investigating how society reacts to domestic violence against women and identifying the factors that contribute to public responses.

\section{Literature Review}

Over the years, majority of society has seen violence between married couples as personal problems that cannot be interfered (Khan, 2015; Oon et al., 2016; Carlson, 2005). Previously from global context, criminal justice system has been criticized in processing domestic violence cases when the problem of violence against women was brought to the attention of the public and policy makers. In addition, police were criticized because they did not take domestic violence cases seriously and were reluctant to arrest the perpetrators unless there are serious injuries of victims due to physical abuse (Fagan and Browne, 1994). Prosecutors were criticized because they too often dismissed wife assault cases, contributing to disincentives for police to arrest. Judges have been criticized too for their reluctance to impose serious sanctions, or to utilize intermediate sanctions such as probation and mandated treatment for batterers, unless victims were seriously injured (Fagan and Browne, 1994). The system in general has been criticized for being insensitive to victims' needs.

However, since late 1970s, reforms in criminal justice policy and practice have increasingly addressed the problems of victims. In Malaysia, Domestic Violence Act has been amended for the second time in 2017 where the improvised definition has been added (Aziz et al., 2018a). Domestic violence now includes acts which cause the victim to fear for her safety, property or a third person or causing her distress. It also includes any communicative acts with an intention to insult the victim's modesty. This is essential to broaden the scope of domestic violence to enhance prevention of various types of abuses. On top of that, public policy makers and practitioners begun to systematically improve and innovate the strategy or interventions through programs aimed at increasing victim and witness reporting, improving victims' access to the legal system and social services, initiating public information campaigns, and continues education support for primary prevention. These innovations are critical in increasing community awareness and intervention as well as responsive public which acts as imperative elements of any strategy aimed in combating domestic violence against women.

Understanding that domestic violence may affects live and work performance(Idris et al., 2018), many studies have been conducted to identify the risk factors that contribute to the occurrences of domestic violence (Aziz et al., 2018a; Capaldi, Knoble, Shortt, \& Kim, 2012; Flury, Nyberg, \& Riecher-Rössler, 2010; Gil-González, Vives-Cases, Ruiz, Carrasco-Portiño, \& Álvarez-Dardet, 2008; Idris et al., 2018; Laeheem, 2016; Mavrikiou, Apostolidou, \& Parlalis, 2014; Stith, Smith, Penn, Ward, \& Tritt, 2004). However, only a few studies have been conducted to determine how the society responses to the issue of domestic violence(Ahmad, Driver, McNally, \& Stewart, 2009; Bagshaw, Chung, Couch, Lilburn, \& Wadham, 2000; Clark, Burt, Schulte, \& Maguire, 1996; Kaur \& Garg, 2010; Laeheem, 2016, 2017; Lund, 2014; Naved, 2013; Sallan Gül, 2013). The following sub-topic will discuss about the factors that hinder the community to response to domestic violence.

\section{Culture and Tradition}

The responses that are expected to be done by local communities including surveillance of domestic violence situations, offering support to victims, and challenging men to stop violence (Unicef, 2000). Several studies have discussed about the reasons of society for not responding to the case of domestic violence (Ahmad et al., 2009; Bagshaw et al., 2000; Kaur \& Garg, 2010; Laeheem, 2016, 2017; Lund, 2014; Naved, 2013). One of the reason is most of violence often happens behind closed doors (Bagshaw et al., 2000). Some culture consider domestic violence is a personal matter between husbands and wives, in which outsiders should not interfere (Laeheem, 2017; Sallan Gül, 2013). Even though community members are aware of the occurrence of domestic violence, they do not feel that they can be involved because 'it is not their business' (Bagshaw et al., 2000). The attitude of "do not disrupting the affairs of others" is worse in urban areas where people are busy at work so there is no time to recognize and greet the neighbours. As compared to rural areas, 
communities are aware of each other and people talk to each other so they often can be expected to respond appropriately to the issue of domestic violence occurring in their neighbourhood (Clark et al., 1996). People often agree that husbands and wives should solve their own personal problems (Kaur \& Garg, 2010). The possible explanation is that often people who are trying to interfere with other people's affairs or trying to disperse fights in the family will later be treated as if it was their fault (Bagshaw et al., 2000). This culture is an impetus to the indifference of society to the cases of domestic violence that is happening around them.

\section{Social Stigma}

In countries that are highly regarded by customs and traditions, family violence is commonly considered as bringing shame to the family. In response to these customary practices, members of the community may refrain from exacerbating the situation or punishing the perpetrator (Bagshaw et al., 2000). Socialstigma is seen not only failed to recognize wives who are victims of sexual abuse, but also interfere with the victim's confession, as they are concerned with the perception of society towards them (Naved, 2013). Some studies linking negative stigma as a community response to women who are victims of intimate partner abuse. Society often associates husband's abuse of the wife with the failure of marriage, which indirectly induces shame among victims and their parents (Ahmad et al., 2009; Lund, 2014).

Some studies have found that social stigma is among the reasons why domestic violence victims are not seeking help and reluctant to disclose their suffering (García-moreno, Claudia; Jansen, Henrica; Ellsberg, Mary; Heise, Lori; and Watts, 2005; Ghimire, Axinn, \& Smith-Greenaway, 2015; Rodriguez, Quiroga, \& Bauer, 1996) especially those suffered with sexual abuse (Naved, 2013). This allegation is parallel to the study done by Ludermir, Lewis, Valongueiro, De Araújo, and Araya (2010)that violence may under-reported due to social stigma and shame. There is also a recent study (Evans \& Feder, 2016) found that the delay in obtaining help amongst victims of abuse was obviously due to social stigma arising from exposing domestic violence to their work colleagues. In short, social stigma is not only one of the causes of community for not responding to the issue of domestic violence, but it also becomes a barrier to victims to seek help.

\section{Lack of Knowledge of Public's Right}

Some study have been conducted on employers' and supervisors' perception toward intimate partners violence in the workplace (Samuel, Tudor, Weinstein, Moss, \& Glass, 2011). Their findings show that many employers and supervisors have expressed their concerns over an employee who has experience intimate partner violence, but often states that they do not know what the best response should be. The probable reason is that sometimes the violent behaviour of the perpetrators towards the victim also scare witnesses to lodge a police report (Laeheem \& Boonprakarn, 2016). Lack of knowledge about the act that protects the safety of the complainant becomes a barrier to employers to assist workers who experience domestic violence.

Most members of the community are unaware of the existence of the Domestic Violence Act 1994 (Parliament of Malaysia, 2017). The section, among others, provides that any person having reason to believe that a domestic violence offense has occurred, or is happening, may provide information to the enforcement officer or the police. Such provision creates immunity protection for the complainant from any defamation liability, if the report is found to be inaccurate or incorrect. In short, the provision provides the right to any person in society to do something in addressing the issue of domestic violence, which is to report the matter to the authorities.

Members of the community do not have to witness the violence and legal provisions say that only if any individual is suspected or there is a good reason for the perception that domestic violence has been or is happening(Parliament of Malaysia, 2017). The provisions of this law clearly set aside the attitude of the society to "not interfere with other people's affairs" in dealing with the issue of domestic violence in our society. Hence, it is clear that with the application of section 18 of the 1994 ACT, people should not blind the eyes, deafening or closing their hearts in dealing with the household violence in our society today. 
Community members need to be sensitive to the environment and understand what is domestic violence and its impact on religion, race and nation.

\section{Methodology}

Researchers and social activists claimed that the women related campaigns and services that exist today began with research on women's experience that has been previously neglected. Thus, starting with real life experiences is a powerful tool which provides the rationale for women's research. Qualitative research method is utilized in this research mainly because there is a need for in-depth understanding of a social phenomenon. A qualitative research seeks to gain first hand holistic understanding of a phenomenon, using flexible methods such as interviews and discussions. It is aimed at gaining the subject's experience of a certain phenomenon. A qualitative approach has the advantage of being flexible it allows the interviewer to respond to new theories and concepts raised by respondents. This research method is appropriate for this study because the researcher intends to gain information of women victims and witnesses of domestic violence from own accounts.

A purposive sampling procedure was used to identify women or men who have been known to be the witnesses of domestic violence in public. Purposive sampling is based on the decision of the researcher. Participants were found through social activists group in JEiWA who are willing and consent to participate in this research. Further, focus groups consisting of domestic violence victims and social activist who have experience on domestic violence will be used. The aim of sampling is to get an approximate representation of the possible target population. The samples must fulfill three main criteria that include women and men holding at least high school certificate, they are in good health which makes them capable to respond realistically and have experienced with domestic violence situation in public as a witness of that violence incidents.

This approach utilizes interviews with each participant in order to create a natural atmosphere which elicits more information. Thus, in-depth interviews with the witnesses of domestic violence were employed in this study. Further, the method will enable the researcher to follow up particular interesting issues that will emerge during the interviews and the participants will be able to give a clear picture. Out of 18 samples contacted, the researchers managed to get responds from 14 of them (all are Malays); which makes the $77.8 \%$ response rate. A summary of the respondents' profiles can be referred in Table 1. Personal interviews were conducted by researchers to collect important data and information. The data and information were then analysed using interview coding and themes. In order to protect confidentiality of the respondents, their real names are concealed and were recoded as Respondent 1 to Respondent 14.

\section{Findings}

Demographic profile of the fourteen respondents that have been interviewed in this study is as shown in Table 1.

Table 1: Demographic Profile of Respondents

\begin{tabular}{lllll}
\hline Respondents & Age & Gender & Education & Profession \\
\hline 1 & 42 & F & Diploma & Businesswoman \\
2 & 37 & F & Diploma & Businesswoman \\
3 & 37 & F & Secondary & Businesswoman \\
4 & 56 & F & Bachelor Degree & CEO \\
5 & 38 & M & Diploma & Businessman \\
6 & 62 & F & Secondary & Housewife \\
\hline
\end{tabular}




\begin{tabular}{lllll}
\hline 7 & 37 & F & Diploma & Nurse \\
8 & 47 & F & Master Degree & Senior Officer \\
9 & 38 & M & Bachelor Degree & Engineer \\
10 & 30 & M & Bachelor Degree & Architect \\
11 & 66 & M & Bachelor Degree & Manager \\
12 & 46 & M & Bachelor Degree & Businessman \\
13 & 55 & M & Secondary & Marketing Officer \\
14 & 37 & F & Master Degree & Lecturer \\
\hline
\end{tabular}

Overall, respondents reported substantial experience with domestic violence, as reported in the next sub-topic. Few of respondents personally know the victims and experienced the situation while the other respondents did not know the victims.

\section{Culture and Tradition}

Respondent \#1 (female, 42 years old) who is a businesswoman and holds a diploma mentioned that she refused to interfere with other people's affairs even though she witnessed the quarrelling of a couple in front of her. She describes her thoughts as:

"I did not want to interfere in their arguments even though the man kept pushing his partner... that was their personal matter"

Respondent \#4 (female, 56 years old) and Respondent \#10 (male, 30 years old) also shared the same reason and expressed their sense of innocence when letting a woman be assaulted by her husband. Considering that the husband and wife quarrel was common, they said:

“...a husband and wife quarrel is normal. It is a common marital problem, why we should interfere in their fighting” (Respondent \#4).

"I did not want to get involved in their problems, they should solve by their own" (Respondent \#10).

Respondent \#7 (female, 37 years old) who are a CEO is also often see rudeness occurs between intimate partners. However, the busyness of the job and always struggling with juggling multiple roles (employer, mother, and wife) she feels unimportant to interfere with other people's affairs, while she has many commitments to be fulfilled. She said:

"I am too busy to disrupt with their personal affairs, that was not my own business"

Respondents \#14 (female, 37 years old) shared that she was afraid to interfere with other people's affairs. Her good intentions to help her neighbours from being victims of emotional and financial abuse end up with allegations of wanting to destroy their marriages. She said:

"My neighbours are often abused emotionally and financially by her husband. While crying she came to my house telling me their problem. I advised her to get counselling ...then when her husband knows about it, he accused me of inciting his wife, and not allowing his wife to be friends with me again. After a few days I saw the couple reconcile... they go out for dinner together and buy some groceries. So I concluded that each spouse had their own problems and fighting in many ways. Yesterday they had quarrel, today they are reconciled. The next day they fight again, next month we heard that his wife was pregnant. So I think it's better not to interfere with other people's affairs to maintain friendship / neighbourhood relationships". 
From all the instances above, a conclusion can be made as to why public are not keen to intervene on domestic violence. The one and only obvious reason being that even though the act may seemed to be very violent but in the end the victims still succumb to their predicament. They often forgive their abusing partners and live on like nothing had ever happened to them. Victims of domestic violence are mostly forgiving and had developed a certain kind of immunisation towards the abuse they received and this had actually deterred public intervention. Only few victims had actually seek help and feared for their lives whilst others had accepted that it is fated for them to be abused and that they want to be with their partners notwithstanding the pain they suffer.

A research should be done not only on the perpetrators as to why they administer violence on their partners, but also on the victims as to why they are willing to go on with their abusive lives. Such research should also include on those victims who decided to report on their abusive partners and had better lives after that. What elements do they possess and what trigger them to end violence against them. Public intervention will not happen because they had predicted that most victims in the end withdrew reports against their partners out of love.

\section{Social Stigma}

Some respondents also questioned the reasonableness of the public to interfere with other couples because it involves not only the dignity of the victim and the perpetrator, but also the dignity of their parents. The possible reason is perhaps they imagine themselves to be embarrassed if their home affairs are intercepted by strangers, and this imagination restricts them to do so in order to prevent victims from being embarrassed. Respondent \#3 (female, 37 years old) and Respondent \#6 (female, 62 years old) share the same opinion with regard to the embarrassment that would be suffered by the victim.

"They will feel ashamed if I offering my help because marital problems were really affect the whole family's name, especially if it involves the substances abuse". (Respondent \#3)

"I did not want to interrupt or get involved in their personal problem, I believe that victim may feel shame if I offer any help". (Respondent \#6)

Such views will make witnesses to pretend to not hear quarrels or pretend not to know about the couple's problem to prevent the victim from being embarrassed. Another two male respondents attributed the issue of dignity that would have been scratched if an outsider interfered with one's household problem. Respondent \#9 (male, 38 years old) who work as an engineer said that:

"I have witnessed such as violent behaviour of my neighbour to her wife, but I can't interfere as it would affect his dignity"

Respondent \#12 (male, 46 years old) who is a businessman describing the unpleasant feelings of interfering with the arguments of the spouses as:

"That was really personal marital issues that can't be interfered or it would affect their relationship and family's dignity"

Furthermore, we also found that gender ideology is also one of the factors that affect the public's reaction to domestic violence issues. This finding is in line with the argument of recent studies(Aziz, Idris, Ishak, Wahid, \& Yazid, 2018b; Idris et al., 2018) who mentioned that if someone identifies themselves with the status of marriage is of the 'tradition' type, then they believe that the husband should be the main breadwinner and the wife must stay at home(Aziz et al., 2018b). Based on this ideology, the older male respondent agrees that hitting the wife is appropriated for some husbands to teach his wife. Respondent \#13 (male, 55 years old) said: 
"Men who beat up their wives, do it to discipline their wives, they beat them up so that the women can recognize their positions as heads of the house"

There are some groups of people who believe that they belong to a certain group of people. In some countries the best group of people is dignified people who are often regarded as the highest rank of all groups of people. This dignity is often based on wealth and good family. It is important for these kinds of people to maintain the two elements to stay in the highest rank. They must maintain their wealth and must not have divorce history in their lines of family tree. Hence if any of they are involved in domestic violence, it remains as secrets within their families as it will bring shame and they will immediately be out casted by the group members. As a conclusion domestic violence against family dignity, the latter holds more water. Social status is often being the highest importance than an individual's personal interests. Due to this social stigma plays an important role in non-intervention by public as the public are not aware.

\section{Knowledge and Use of Public's Right}

The following four respondents expressed their sympathy for the victims, but they were more concerned with their safety. This finding is in line with a study done by Laeheem and Boonprakarn (2016) who found that the violent behaviour of perpetrators sometimes scare witnesses to lodge a police report. Respondent \#2, \#5 and \#11, share the same views with regard to their own safety concerns:

"I am very scared, shocked and cannot offer any help, I want to report that incidents to police but I am afraid that the perpetrators will know about this and have revenge on me"(Respondent \#2, female, 37 years old),

"I did not want to interfere because this was their family matters, if anything happened to me, who will look after my family?” (Respondent \#5, male, 38 years old)

"I did not know them, why should I interfere to help, who will protect me if the perpetrator beat me up?" (Respondent \#11, male, 66 years old)

The anxiety about their own safety may also be attributed to a lack of knowledge of the Domestic Violence Act 1994 which protects the complainant. In fact, respondents also lack of knowledge on how to deal with the offenders. Respondent \#8 (female, 47 years old) said that she felt sympathy with the victim but felt uneasy to give helps. She said:

"Actually, I want to offer my help, but I do not know what is the best response should be done"

Previous studies highlighted that most domestic violence victims do not know whom they complain and do not know the form of assistance and protection services that are available in a country. Lack of knowledge causes women to survive in fear, continues to be victims of domestic violence and continues to tolerate with unhealthy relationships. Hence, victims surrounded by people who do not know how to take action to help them certainly will exacerbate the emotions of the victim. The results of this study may inform public about the information of initiatives or what they should do when it occurs because there are few peoples believe that partner violence is normal or acceptable. There is a need to convince the public that domestic violence is a serious marital problem which is illegal, or that it calls for police intervention. The public may be misinformed about other issues, such as the difficulties women faced when involved with violent relationships.

\section{Conceptual Model and Research Propositions}

This study attempts to identify the factors that influence public reaction to domestic violence against women. Each factor is studied using a detailed literature review and in-depth interview as discussed above. Hence, a conceptual model is proposed as presented below which is in line with literature review and supported by our research findings. 


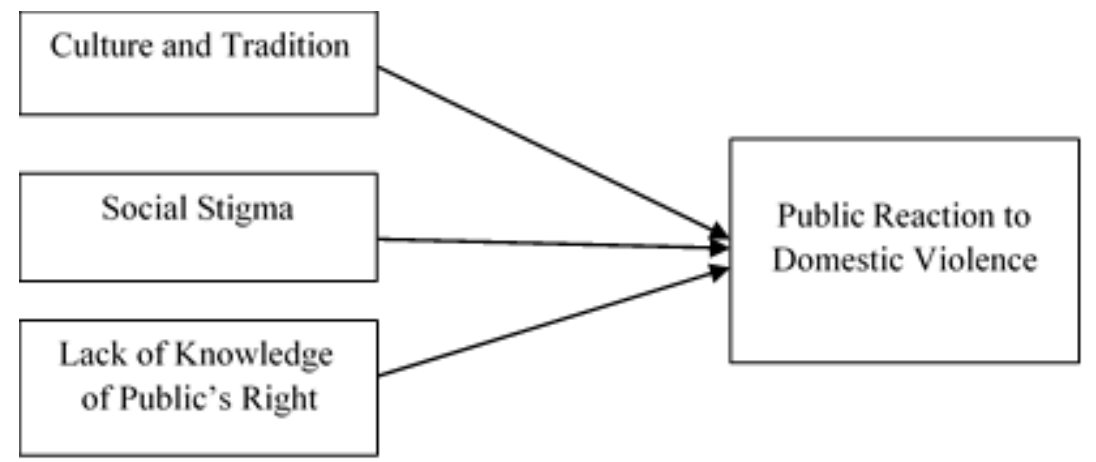

Figure 2 Conceptual model

As Figure 2 illustrates, the arrangement of the model suggests that there are three main factors that may influence the public reaction to domestic violence against women namely, culture and tradition, lack of knowledge of public's right and social stigma. Considering the negative culture, social stigma and lack of knowledge about the right of the public enshrined in the Domestic Violence Act 1994 may influence public responses to domestic violence, we thus make the following propositions:

Proposition 1:Culture and tradition has a significant effect on public reaction to domestic violence.

Proposition 2:Social stigma has a significant effect on public reaction to domestic violence.

Proposition 3:Lack of knowledge of public's right has a significant effect on public reaction to domestic violence

\section{Discussion}

\section{The Challenges in Community Reactions to Domestic Violence}

In order to help women faced with domestic violence, there are numerous efforts taken by governments, NGOs and even individuals. There are many NGOs offering aids and even shelters for domestic violence victims throughout the world and these NGOs have been updating their designs on how to help these kinds of women. This is evident from a number of implementations of interventions to reduce the number of domestic violence offences. The effectiveness of aids offered by NGOs are often subjective (Akyüz \& Sayan-Cengiz, 2016) as the healing process taken by victims are often slow. Many factors contribute to whether such aids are helpful or not. In an article by UN Women, Ending Violence against women, failures of aids provided by NGOs are because lack of legal intervention. In some countries, domestic violence offences are regarded as 'private affairs'.

Domestic violence is not regarded to be a serious offence as the perception by some countries is domestic or internal family issues (Laeheem, 2017; Sallan Gül, 2013). Hence no matter what length of help that NGOs provide to the victims will not be effective as there are no sanctions to the offenders. Victims are left unprotected. Victims of domestic violence usually suffer in silence (O'Brien, Cohen, Pooley, \& Taylor, 2013; Rodriguez et al., 1996). In an article by healthtalk.org, women's experiences of domestic violence and abuse, victims are sometimes too scared of their abusive partners to report on them due to emotional blackmail often administered by the offenders to the victims. Most victims never approached anyone (Samuel et al., 2011) to 
get help and therefore NGOs could not exercise aids for them. This is another factor which contributes to the failure to help victims.

Public non-intervention also plays a major role in minimising domestic violence offences. In the same article, a research was done by re-enactment of public display of domestic violence. Hidden cameras showed that public will just shun away and never bothered to interrupt or help domestic violence victims.

\section{Strategic Interventions}

Among the parties who are highly responsive to the issue of domestic violence are non-government organizations (Wijayatilake \& Guneratne, 2002). In Malaysia, there are 873 non-governmental organizations in the category of women's organizations, in which 147 of them using the name of "Women's Welfare Organization / Association". Information from the Women Department's official website also listed 32 NGOs under the category of violence against women. These organizations generally are independent bodies, notreligious, non-profit, and is committed to the fight any violence against women. These NGOs are also involved in educating the community, especially women on issues of domestic violence, discrimination against women and women's rights. Sometimes NGOs have also played a role in providing temporary shelter to women who are victims of violence. These services offered by NGOs are essential in determining the success of the community in dealing with domestic violence (Shepard, 1999).

In a nutshell, most women NGOs are set up with the goals of (1) providing temporary protection services and on-demand services to women and children suffering from mental, physical and sexual abuse; (2) offering emotional and social support to any woman who asks for it; (3) organizing programs to raise awareness and better understanding among individuals, and public agencies on issues of violence against women; (4) conducting research on any of the factors that contributed to the conquest and violence against women; and (5) conveying the voice of women through legal reforms, policies and institutions.

\section{Government Interventions}

Department of Women Development under the Ministry of Women, Family and Community have been actively initiating programs for the empowerment of women specifically to fight violence against women because the issue impacts not on the victim, but the family, society and the whole nation. Thus, the AntiViolence Campaign is a major event by the Department, in collaboration with various governmental and nongovernmental agencies to educate the community that violence against women is a human rights violation and a global pandemic. The government is reaching out to the community to create awareness among the public on everyone's roles and responsibilities in addressing all forms of violence against women.

Realising the impact on the violence against women to the society and the country, especially on the health and wellbeing of the victims (Idris et al., 2018) and the nation, prevention is always possible and essential. Therefore, various activities held in different states, with multiple layers of target group both urban and rural areas. For instance, 'Legal Support Groups' for women who are seeking legal a domestic violence on violence issues are available at all states. This support groups are aimed to increase legal literacy among women, as they will be educate about what they will go through during divorce process and how the government will help them such as legal domestic violence, fees and support. Other than that, a program called 'Bridge to a better life' is to enhance the psychological well-being of women to be better person, with positive attitudes regardless the challenges they are going through. Participants are being taught to have the ability to stay resilient at any circumstances. The Psychological Support Group will also discuss on how to understand, to identify and to deal with multiple characteristics of the abusers.

At the ground level, the government has trained PERWANI Lay Counsellors (PERWANI 1Malaysia Community). PERWANI Lay Counsellors are so that they can help the women in their communities. PERWANI Lay Counsellor help to educate women to be more knowledgeable, equipted with counselling and 
psychology skills because this will help to accelerate the process of guiding and helping, particularly to address social problems. Since 2017, a total of 172,309 members PERWANI, 5423 members is PERWANI Lay Counselor who have conducted a total of 26,232 counselling sessions with an average PERWANI Lay Counselor and counseling of 1: 4.8 sessions (Faridah Awang, Raja Kamariah, Mohamad, 2017). PERWANI Lay Counsellor activities have been implemented throughout the community level across race, religion and gender in Malaysia. Recognizing the roles and contributions of women for the country's socioeconomic development, family and community wellbeing, the government is vigilant in enhancing the involvement and capacity of women in various sectors to achieve gender equality as the basis towards the creation of a developed nation but first, is to eliminate violence against women.

\section{Legislative Interventions}

Malaysia has a considerable number of domestic violence cases tried in its courts. However, police reported more cases than those that were brought to court. Could the discrepancies in the number of cases between police reports and tried cases caused by loopholes in the law governing domestic violence? The law governing domestic violence in this country dated back since 1994. The Domestic Violence Act 1994 had been the statutory dealing with domestic violence cases in Malaysia. It recognizes all forms of domestic violence as sizable offences (crimes for which the perpetrator can be arrested without a warrant).

How does law enforces punishments and sanctions towards domestic violence perpetrators? The Malay Mail Online dated 26 April 2017 reported that there were 57,519 cases of domestic violence against women since 2010 according to police statistics. Does that big numbers portrays that the Act has not been successful to deter domestic violence? For record, the Domestic Violence Act (Amendment) Bill 2017 has includes the expansion of the Interim Protection Order (IPO) and Protection Order (PO). This includes the permission for the social welfare officers to grant victims of domestic violence immediate protection, without the need to make a police report or receive a court order. In theory IPO is used when there is a pending police investigation. It provides temporary protection until further action can be taken against perpetrators. It could be said that on the contrary the Act is quite thorough to protect and help victims. The Bill also protects victims against offenders who threaten them, or employ third parties to carry out violence against them and offenders who contact victims to harass or embarrass them via any medium, including text messaging (Parliament of Malaysia, 2017).

However, there were cases where IPO breaches went unpunished. This is a dilemma. In 2012, the Act had undergone some amendments whereby a mechanism has been set up via the Malaysian criminal justice system for the purpose of investigating reports, prosecuting the perpetrators and protecting victims of domestic violence. It is supposed to be the most effective method to curtail domestic violence, however, more cases were reported to the police but only a small number were brought to the court. The main contributing factor to the failure to curb domestic violence is because the victims had a low level of knowledge of their legal rights. This is added by the victims' attitude of feeling ashamed to open up and some still have feelings towards the perpetrators. In the broader overview the sentiment of the public towards domestic violence is it is purely a domestic issue where it should be dealt domestically. Sadly no one bother to acknowledge that domestic violence is physical attack equivalent to grievous bodily harm. In fact domestic violence is not only physical attack, there are many other forms which are in the form of mental torture and financial abuse. It is more complex than physical attack as defined in the Criminal Procedure Code.

Now Domestic Violence Act has been amended for the second time in 2017 where domestic violence has a wider definition. Domestic violence now includes acts which cause the victim to fear for her safety, property or a third person or causing her distress. It also includes any communicative acts with an intention to insult the victim's modesty. This is essential to broaden the scope of domestic violence to enhance prevention of various types of abuses. The amended Act also introduced a new order known as the emergency protection order (EPO). Now victims can approach a social welfare worker to get an EPO rather than having to go through lengthy process of making police report in order to get an IPO. EPO protects victims by preventing 
perpetrators from entering victims' safe place or any shared residence. It is issued to the victims within two (2) hours from application and is valid for seven (7) days; ample time for victims to apply for IPO. The amended Act went on to punish abusers who breach EPO (with or without violence).

We see here that now the law is more substantial and had focused more on protecting victims thus intervene domestic violence. It even put a restriction on the courts. This seems to give a negative connotation; restricting court powers when dealing with domestic violence cases. However, this restriction serves as an innuendo to provide more protection for domestic violence victims. Previously, victims can be forced to undergo reconciliatory counselling sessions with their abusers. Now, the courts can no longer order both parties to attend counselling sessions simultaneously. Instead, the courts can order the abusers to complete a rehabilitation session and the victims can only be ordered to attend it if the victims consent to it.

While putting a restriction on the powers of the courts as stated above, the amended Act now gives a new power to the courts. If victims are allowed to continue living in the house they had been living with their abusers during court proceedings, the courts have to grant the victims exclusive occupation over the whole property. This is a good protection for domestic violence victims as opposed to the old law that the courts can only grant exclusivity of only some parts of the property to victims. The above are evidence that the law has been improvised to provide an airtight protection for domestic violence victims hence to further deter and curb the offence from being committed.

\section{The Positive Outcomes of Survivors through Housing Facilities Program}

Most of the available literatures focused on the negative impact of domestic violence against women. Recently, there are emergence of studies, NGOs initiatives and testimonies that speak on how abusive relationship turned women to be more creative and critical thinking. Instead of living in trauma and look at the dead end routes, the positive perspective on dark situations made women seek for help managed to transform their lives and get better opportunities that suits their profiles. Women who suffered from domestic violence relationships are usually unable to leave their partners mainly because lack of financial and housing resources, child support issues, education and employment opportunities, fear of batterer retaliation and social pressure (Bell \&Naugle 2005). Based on article by Bell and Naugle (2005), numerous theories have emerged on evaluating woman's actions in leaving abusive relationships and start new life. The decision to leave an abusive relationship involves not just a single behavior, but a string of behaviors, each potentially under the control of different variables including safety and economic issues which regarded as reinforce (housing facilities).

\section{JEIWA's Initiatives}

The Johor Empowerment of Intellectual Women Association (JEiWA) is a registered non-governmental organisation (NGO) that consists of professional women focusing on helping abused women to start a new life and become new women. The organisation was established in June, 2016 has supported their members from the aspects of legal reference, business opportunities, personality rebranding, spiritual enhancement, women's healthcare and community arts. In August 2018, the Research and Innovation (R\&I) unit has been developed that comprises a group of professional researchers from various backgrounds working together in a committed way towards the research goal. The (R\&I) team is supported by Department of Women's Development, Ministry of Women, Family and Community Development, Malaysia. This organisation advocates for domestic violence prevention through research and strategic program as well as partnership with other governmental agencies and corporate companies. This research collaboration emerged with the express purpose of sharing resources to conduct research that would have an impact on improvement of women's related policy in Malaysia. The Research and Innovation team meets and engage with senior policy makers and advocates at the state and national levels. 
A safe house also known as "RumahSelamat" introduced by JiShian Single Mother Association from Johor Bahru, Johor, Malaysia via collaboration with JEIWA as the facilitator to Iskandar Regional Development Auhtority (IRDA) to provide options for housing facilities for domestic violence survivors. The Safe House is a place where it provides opportunity for battered women to start managing their own lives and continue to make living. The house provides job opportunities and appropriate medical for survivors. The house is located in a strategic location of Iskandar Malaysia and within $10 \mathrm{~km}$ radius of upcoming town of Iskandar Puteri. It offers fresh environment and job opportunities for women where numerous development projects take place. The house is within a gated \& guarded community provide ease of mind for women to continue building their lives. Located within the radius of $5.0 \mathrm{~km}$ from nearby schools, walking distance business areas and transportation hub, it provides survivors confidence and positive assimilation process with available infrastructure within the safe house area. The safe house not only a place to stay but a stepping stone to a better life. The trial period is 14 days and duration of up to two (2) years. Every month the committee will analyse woman's positive transformation through the social support provided not only for their mental health development but also on their domestic violence cases at court (if any) and their children education and medical conditions. The "graduation from safe house" will commence in two (2) years with the aim that survivors can sustain their lives without any support from the committee towards adequate permanent housing.

\section{Limitations and Recommendations}

This study has been restricted by a number of limitations. By recognizing these limitations it is important to provide a viable basis for interpreting the findings of the study as intended. It includes within the research process as well as outside the research process itself. By rectifying the shortfalls of the present research, it helped to address the future research work. This present study utilized an in-depth interview with witnesses of domestic violence in public and a re-enactment video of a true case and it is only intended for the purpose of conducting a study on public reaction witnessing domestic violence virtually instead of a social experimentation video. Thus, future research with social experimentation video is suggested since it may give better insight into the factors and relationships investigated. Recommendations of using a greater number of respondents and other methods of analysis, such as quantitative approach are also encouraged in order to test the significance effect between the factors as presented in the Figure 2 and signify better results that would have stronger governmental implications.

\section{Conclusion}

In general, these findings could inform policy makers about levels of support for innovations of existing interventions. The findings could help policy makers, authorized agencies and non-governmental organizational leaders to strategize and adequately craft a suitable and high impact program that suits the target groups' needs and lifestyle. NGOs and authorised agencies have the responsibility of managing educational campaigns for the whole community that will challenge the belief that domestic violence is a public concern rather than personal concern. The campaign will also help the community to recognize the dangers of domestic violence and report cases such as wife abuse, rape, etc. to the enforcement agent as soon as possible to bring the perpetrator to court.

Campaigns should also stress on the victims that they are responsible to themselves and their children (if any). The safety and well-being of children is closely related with mother's safety. Children may be exposed to various forms of violence when they see their mother being attacked, hearing conflict or a strong quarrels and seeing the consequences of such a disorder. Victims cannot rely on help to be initiated by others. They have to act first. This is the most important step to end domestic violence.Despite many cases of domestic violence recorded by hospitals, police, and the Women's Department, this issue is rarely documented by the mainstream media. Social media should proactively serve as a source of information dissemination in the effort to re-educate society about domestic violence. Information regarding the authority to be contacted if one is aware of the occurrence of abuse cases among neighbours, the existence of NGOs and shelters, and legislation related to women's rights, should be disseminated by social media to the society. With the 
existence of the Act 1994, any person who has only argued that a case of domestic violence has or has occurred should play their part to report to the authorities and to ensure that the community's disease must be stopped. Every member of society should play a role in eradicating or reducing this social illness. Additionally, community members should also take a role in promoting local communities in the importance of their roles and measures to curb these social phenomena together.

The findings of this study are expected to encourage further research to examine more factors that could shed more light on effective interventions. It is hope that this present study can act as a starting point for them to begin their development of such an insight. On top of that, a coordinated community responses is suggested in combating domestic violence. This coordinated local approach includes working together across disciplines to encourage an integrated and consistent approach to the victim, the children and the perpetrators. Such an approach includes the justice, health care, child protection, social services, immigrant settlement, and education systems specifically addressing the needs of victims of domestic violence and of diverse groups. Major reports on violence against women have confirmed the crucial importance of coordination of all sectors, at all levels, across the entire continuum of the response to domestic violence. A coordinated response is particularly important in supporting women who are fearful of proceeding through the justice system and victims who are marginalized or particularly vulnerable. Services that may be available in the community and can potentially be coordinated include justice system supports child supports and health and social supports.

\section{Acknowledgements}

The researchers would like to express sincere appreciation and thank to Johor Empowerment of Intellectual Women Association (JEiWA) and Department of Women's Development, Ministry of Women, Family and Society Development for the great collaboration which provides financial and technical support for this research.

\section{References}

Ahmad, F., Driver, N., McNally, M. J., \& Stewart, D. E. (2009). "Why doesn't she seek help for partner abuse?" An exploratory study with South Asian immigrant women. Social Science and Medicine, 69(4), 613-622.

Akyüz, S., \& Sayan-Cengiz, F. (2016). “Overcome your anger if you are a man”: Silencing women's agency to voice violence against women. Women's Studies International Forum, 57, 1-10. http://doi.org/10.1016/j.wsif.2016.03.004

Aziz, N. N. A., Idris, S. A. M., Ishak, M., Wahid, N. A., \& Yazid, Z. N. A. (2018a). Factors affecting domestic violence against women: a conceptual model and research propositions. International Journal for Studies on Children, Women, Elderly And Disabled, 4(June), 191-198.

Aziz, N. N. A., Idris, S. A. M., Ishak, M., Wahid, N. A., \& Yazid, Z. N. A. (2018b). Understanding the Antecedents of Domestic Violence against Women: A Preliminary Study. In 4th Putrajaya International Conference on Children, Women, Elderly and People with Disabilities (PICCWED 4) (pp. 36-46).

Ghani, M. A. (2014). Exploring Domestic Violence Experience from the Perspective of Abused Women in Malaysia. Doctoral Thesis,Loughborough University.

Bagshaw, D., Chung, D., Couch, M., Lilburn, S., \& Wadham, B. (2000). Family violence in Aboriginal communities (Vol. 1).

Bell, K. M., \& Naugle, A. E. (2005). Understanding stay/leave decisions in violent relationships: A behavior analytic approach. Behavior and Social Issues, 14(1), 21.

Capaldi, D. M., Knoble, N. B., Shortt, J. W., \& Kim, H. K. (2012). A Systematic Review of Risk Factors for Intimate Partner Violencie. Partner Abuse, 3(2), 231-280. http://doi.org/10.1891/1946-6560.3.2.231.A

Carlson, B. E. (2005). The most important things learned about violence and trauma in the past 20 years. Journal of Interpersonal Violence, 20(1), 119-126.

Clark, S. J., Burt, M. R., Schulte, M. M., \& Maguire, K. (1996). Coordinated community responses to domestic violence in six communities: Beyond the justice system. 
Evans, M. A., \& Feder, G. S. (2016). Help-seeking amongst women survivors of domestic violence: A qualitative study of pathways towards formal and informal support. Health Expectations, 19(1), 62-73. http://doi.org/10.1111/hex.12330

Fagan, J., \& Browne, A. (1994). Violence between spouses and intimates: Physical aggression between women and men in intimate relationships. Understanding and preventing violence, 3 .

Flury, M., Nyberg, E., \& Riecher-Rössler, A. (2010). Domestic violence against women: Definitions, epidemiology, risk factors and consequences. Swiss Medical Weekly, 140(NOVEMBER), 23-27.

García-moreno, Claudia; Jansen, Henrica; Ellsberg, Mary; Heise, Lori; and Watts, C. (2005). WHO Multicountry Study on Women's Health and Domestic Violence against Women. WHO World Health Library Catalougue, 19.

Ghimire, D. J., Axinn, W. G., \& Smith-Greenaway, E. (2015). Impact of the spread of mass education on married women's experience with domestic violence. Social Science Research, 54, 319-331. http://doi.org/10.1016/j.ssresearch.2015.08.004

Gil-González, D., Vives-Cases, C., Ruiz, M. T., Carrasco-Portiño, M., \& Álvarez-Dardet, C. (2008). Childhood experiences of violence in perpetrators as a risk factor of intimate partner violence: A systematic review. Journal of Public Health, 30(1), 14-22. http://doi.org/10.1093/pubmed/fdm071

Idris, S. A. M., Aziz, N. N. A., Khalid, R. K. R. M., Nizar, N. F. M., Rasip, K. A., \& Ayub, W. (2018). Causes and effects of domestic violence: a conceptual model on the performance at work. International Journal for Studies on Children, Women, Elderly And Disabled, 4(June), 199-207.

Kaur, R., \& Garg, S. (2010). Domestic violence against women: A qualitative study in a rural community. AsiaPacific Journal of Public Health, 22(2), 242-251.

Khan, A. R. (2015). Domestic Violence against Women in Bangladesh: A Review of the Literature and the Gaps to fill-in by Future Interventions. Khazar Journal of Humanities and Social Sciences, 18(3), 57-81.

Laeheem, K. (2016). Factors affecting domestic violence risk behaviors among Thai Muslim married couples in Satun province. Kasetsart Journal of Social Sciences, 37(3), 182-189. http://doi.org/10.1016/j.kjss.2016.08.008

Laeheem, K. (2017). The effects of happy Muslim family activities on reduction of domestic violence against Thai-Muslim spouses in Satun province. Kasetsart Journal of Social Sciences, 38(2), 150-155. http://doi.org/10.1016/j.kjss.2016.05.004

Laeheem, K., \& Boonprakarn, K. (2016). Family background in upbringing, experience of violence, and authority relationship among married, Thai, Muslim couples in Pattani province experiencing domestic violence. Kasetsart Journal of Social Sciences, 37(2), 93-99.

Ludermir, A. B., Lewis, G., Valongueiro, S. A., De Araújo, T. V. B., \& Araya, R. (2010). Violence against women by their intimate partner during pregnancy and postnatal depression: A prospective cohort study. The Lancet, 376(9744), 903-910. http://doi.org/10.1016/S0140-6736(10)60887-2

Lund, I. O. (2014). Characteristics of a national sample of victims of intimate partner violence (IPV): Associations between perpetrator substance use and physical IPV. NAD Nordic Studies on Alcohol and Drugs, 31(3), 261-270.

Mavrikiou, P. M., Apostolidou, M., \& Parlalis, S. K. (2014). Risk factors for the prevalence of domestic violence against women in Cyprus. Social Science Journal, 51(2), $295-301$. http://doi.org/10.1016/j.soscij.2014.02.002

Naved, R. T. (2013). Sexual violence towards married women in Bangladesh. Archives of Sexual Behavior, 42(4), 595-602. http://doi.org/10.1007/s10508-012-0045-1

O’Brien, K. L., Cohen, L., Pooley, J. A., \& Taylor, M. F. (2013). Lifting the Domestic Violence Cloak of Silence: Resilient Australian Women's Reflected Memories of their Childhood Experiences of Witnessing Domestic Violence. Journal of Family Violence, 28(1), 95-108. http://doi.org/10.1007/s10896-012-9484-7

Oon, S. W., Shuib, R., Ali, S. H., Endut, N., Osman, I., Abdullah, S., \& Ghani, P. A. (2016). Exploring the Coping Mechanism of Women Experiencing Intimate Partner Violence in Malaysia. SOCIONT $20163 \mathrm{rd}$ International Conference on Education, Social Sciences and Humanities, (May), 820-825.

Parliament of Malaysia. (2017). Laws of Malaysia Act 302 (Vol. 1449).

Rodriguez, M. A., Quiroga, S. S., \& Bauer, H. M. (1996). Breaking the silence. Battered women's perspectives on medical care. Archives of Family Medicine, 5(3), 153-8. 
Sallan Gül, S. (2013). The role of the State in protecting women against domestic violence and women's shelters in Turkey. Women's Studies International Forum, 38, 107-116.

Samuel, L. J., Tudor, C., Weinstein, M., Moss, H., \& Glass, N. (2011). Employers' Perceptions of Intimate Partner Violence among a Diverse Workforce. Safety and Health at Work, 2(3), 250-259. http://doi.org/10.5491/SHAW.2011.2.3.250

Shepard, M. (1999). Evaluating Coordinated Community Responses to Domestic Violence. VAWnet Applied Research Forum, (April), 545-9456.

Shuib, R., Endut, N., Ali, S. H., Osman, I., Abdullah, S., Oon, S. W., ... Shahrudin, S. S. H. (2013). Domestic Violence and Women's Well-being in Malaysia: Issues and Challenges Conducting a National Study Using the WHO Multi-country Questionnaire on Women's Health and Domestic Violence Against Women. Procedia Social and Behavioral Sciences, 91, 475-488.

Stith, S. M., Smith, D. B., Penn, C. E., Ward, D. B., \& Tritt, D. (2004). Intimate partner physical abuse perpetration and victimization risk factors: A meta-analytic review. Aggression and Violent Behavior, 10(1), 65-98. http://doi.org/10.1016/j.avb.2003.09.001

Unicef. (2000). Domestic violence against women and girls. Innocenti Digest, (6), 1-22.

Uzun, G. O., \& Uzunboylu, H. (2015). A Survey Regarding of Domestic Violence Againts Women. Procedia Social and Behavioral Sciences, 190(November 2014), 24-31.

World Health Organisation (WHO), (2013). Global and Regional Estimates on Violence against Women. WHO Library Cataloguing-in-Publication Data, ISBN 9789241564625

Wijayatilake, K., \& Guneratne, C. (2002). State and Community Responses to Domestic Violence in Sri Lanka. 